\title{
The Effects of Laser Surface Modification on the Microstructure of 1.4550 Stainless Steel
}

\author{
Damian Przestacki ${ }^{1}$,, Aneta Bartkowska ${ }^{1}$, Mateusz Kukliński ${ }^{1}$ and Piotr Kieruj ${ }^{1}$ \\ ${ }^{1}$ Poznan University of Technology, Marii Sklodowskiej-Curie 5 St., 60-965 Poznan, Poland
}

\begin{abstract}
In this study a stainless austenitic steel 1.4550 was laser heat treated with diode laser. The influence a gouache coating on remelted steel substrate was carry out. The cooling system during laser melted was analysis as well. Melted layers were manufactured with different laser beam power between $0.6 \mathrm{~kW}$ and $1.4 \mathrm{~kW}$, constant scanning laser beam speed $v_{l}=5.76 \mathrm{~m} / \mathrm{min}$ and laser beam diameter equal $d_{l}=1.2 \mathrm{~mm}$. The surface was treated at room temperature and under $\mathrm{CO}_{2}$ cooling conditions and the results were compered. With the increase of the laser beam power, the dimensions of the laser tracks increase. The depth of laser tracks varies significantly than their width. The deepest melted layer was observed for a material that wasn't coated by any of absorbent paste and when there wasn't cooling system.
\end{abstract}

\section{Introduction}

One of new techniques improving machinability of material is laser assisted machining often reffered to as LAM [1-5]. The technique of laser assisted turning concentrates on improving machining of material due to increasing temperature in cutting zone which results from interaction with laser beam [1-5]. However, before undertaking attempts of hybrid machining (simultaneously heating and turning of machined material) it is significant to investigate what is happening what happens with material after only laser heating process [5-7]. Analysis of microstructure and microhardness significantly demonstrates these changes [1-15].

In many publications problems connected with laser heating of material and changes occurring in them are analyzed [1-19]. Mainly, they concern ferrous alloys [4,8,9], nickel alloys [6,7,13] or titanium alloys [2]. Group of hard-to-cut materials includes undoubtedly alloys reinforced with $\mathrm{SiC}$ and WC particles [10-12,15]. Recently, scientific research focuses on difficult-to-cut materials, which use are constantly increasing in industry [14-19]. Among ferrous alloys, steels containing extended content of nickel and chromium, ex. austenitic steel, may cause problems with machining.

Nowadays there is a tendency to manufacture products of higher quality in shorter time and with lower costs. To achieve some of mentioned objectives, it is necessary to use hard and resistant materials which usually have low machinability. Therefore, the objective of this research was to determine adequate parameters for laser assisted turning of commonly used austenitic steel.

\section{Experiments}

\footnotetext{
${ }^{a}$ Corresponding author: damian.przestacki@put.poznan.pl
} 
Specimens of stainless austenitic steel 1.4550 were laser heat treated using diode laser TruDiode 3006 produced by Trumpf company. In the research, influence of impact of applied coating - gouache of thickness equal to approximately $20 \mu \mathrm{m}$ and of $\mathrm{CO}_{2}$ cooling system during interaction of laser beam with the material. All significant parameters of laser heat treatment are shown in table 1. During laser heat treatment constant laser beam scanning velocity and laser beam diameter were applied, equal to respectively $v_{l}=5.76 \mathrm{~m} / \mathrm{min}$ and $d_{l}=1.2 \mathrm{~mm}$. On the other hand, laser beam power was variable and equal to $P=600 \mathrm{~W}, P=1000 \mathrm{~W}$ i $P=1400 \mathrm{~W}$.

Table 1. Laser heat treatment parameters

\begin{tabular}{|c|c|c|c|c|}
\hline$P$ & $d_{I}$ & C & Coolino & \\
\hline$[\mathbf{W}]$ & {$[\mathrm{mm}]$} & Coating & Coving & {$[\mathrm{m} / \mathrm{min}$} \\
\hline 600 & \multirow{12}{*}{1.2} & \multirow{6}{*}{$\begin{array}{l}\text { gouache } \\
\text { coating }\end{array}$} & \multirow{3}{*}{ without } & \multirow{12}{*}{5.76} \\
\hline 1000 & & & & \\
\hline 1400 & & & & \\
\hline 600 & & & & \\
\hline 1000 & & & $\mathrm{CO}_{2}$ & \\
\hline 1400 & & & & \\
\hline 600 & & \multirow{6}{*}{$\begin{array}{l}\text { without } \\
\text { coating }\end{array}$} & \multirow{3}{*}{$\mathrm{CO}_{2}$} & \\
\hline 1000 & & & & \\
\hline 1400 & & & & \\
\hline 600 & & & \multirow{3}{*}{ without } & \\
\hline 1000 & & & & \\
\hline 1400 & & & & \\
\hline
\end{tabular}

Specimens of dimensions $26 \mathrm{~mm} \times 10 \mathrm{~mm}$ × $6 \mathrm{~mm}$ after laser heat treatment were included in thermosetting resin. Then, specimens were grinded with abrasive papers of degressive gradation, polished using alumina oxide suspension and etched with glycerin reagent. To carry out microscopic observations light microscope OPTA-TECH of LAB 40 series was used both with OptaViewIS software. Moreover microhardness testing with Vickers method was carried out, using load of $100 \mathrm{~g}$ (HV0.1) on Zwick 3212B microhardness tester.

\section{Results of experiment}

Figure 1 presents influence of laser beam power without applying initial coating and without applying cooling system during laser heat treatment. It can be seen that with increasing laser beam power, dimensions of laser tracks also increase, in particular their depth. With applied parameters of laser heat treatment without initial coating and without applying cooling system during laser heat treatment, obtained laser tracks are free of pores and cracks.
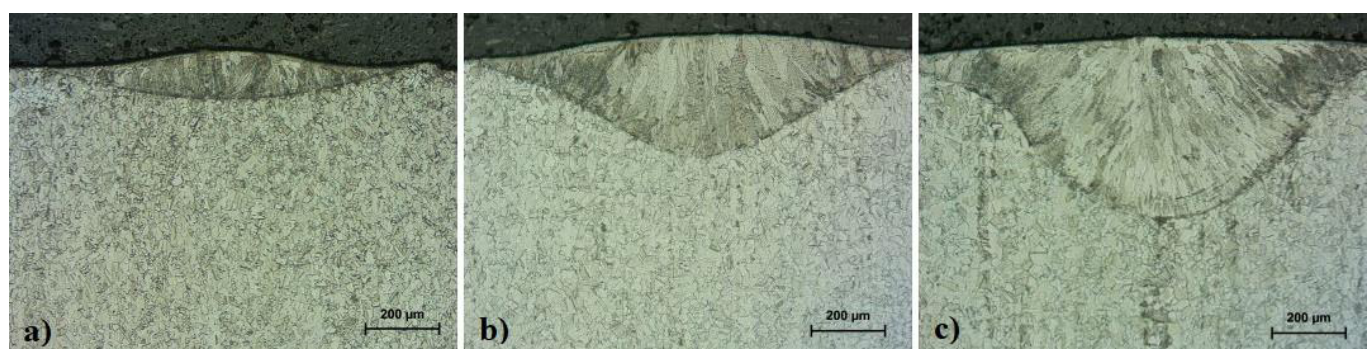

Figure 1. Microstructure of 1.4550 steel after impact of laser beam without initial coating and without cooling during laser heat treatment; a) $600 \mathrm{~W}$, b) $1000 \mathrm{~W} \mathrm{c)} 1400 \mathrm{~W}$

Figure 2 presents influence of laser beam power if initial gouache coating is applied and without applying cooling system during laser heat treatment. It can be seen that increasing laser beam power 
dimensions of laser tracks also increase. Depth of laser tracks changes significantly. Also in this case applied laser heat treatment parameters resulted in obtaining layer free of cracks and pores.
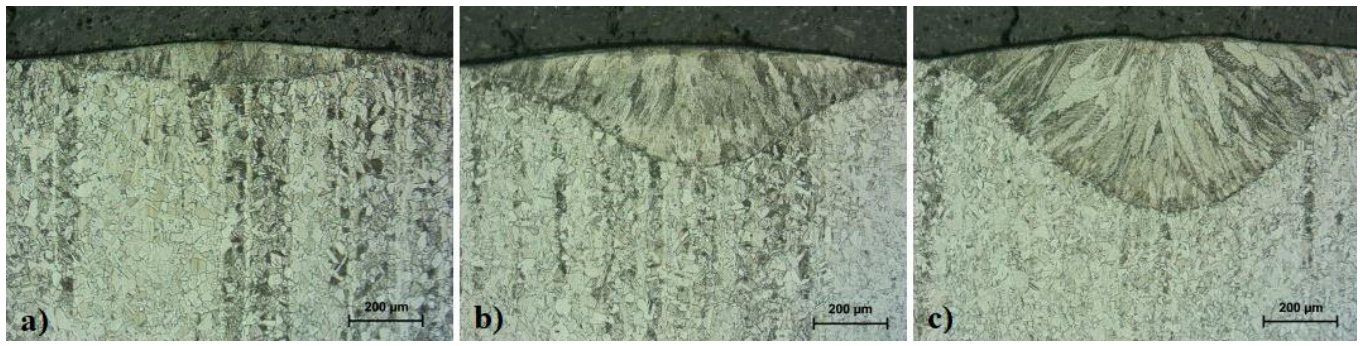

Figure 2. Microstructure of 1.4550 steel after impact of laser beam with initial gouache coating and without cooling during laser heat treatment; a) $600 \mathrm{~W}$, b) $1000 \mathrm{~W}$ c) $1400 \mathrm{~W}$

Figure 3 presents influence of laser beam power without applying initial coating but with applying $\mathrm{CO}_{2}$ cooling system. Usage of increasing laser beam power results in obtaining larger dimensions of laser tracks. Especially changes can be seen if depths of laser tracks are analyzed. With applied laser heat treatment parameters without applying initial gouache coating and with applying $\mathrm{CO}_{2}$ cooling system during the process obtained laser tracks are free of pores and cracks. Only near the surface fine crystals oriented perpendicularly to the surface can be seen and they were not visible on laser tracks obtained when cooling system was not applied.
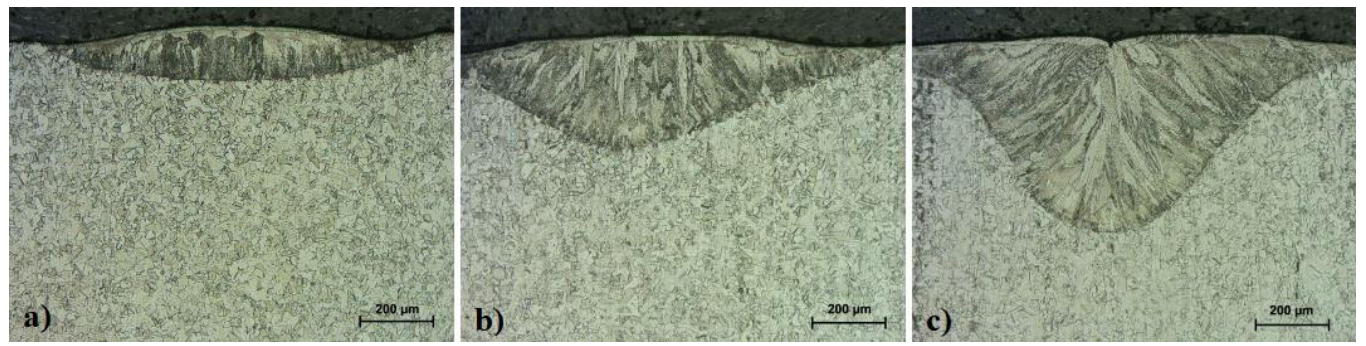

Figure 3. Microstructure of 1.4550 steel after impact of laser beam without initial coating and with $\mathrm{CO}_{2}$ cooling system during laser heat treatment; a) $600 \mathrm{~W}$, b) $1000 \mathrm{~W}$ c) $1400 \mathrm{~W}$

Figure 4 presents influence of laser beam power with applied both initial gouache coating and $\mathrm{CO}_{2}$ cooling system during laser heat treatment. It can be seen that with increasing laser beam power the relation is maintained and the higher laser beam power, the larger dimensions of laser tracks.

If low laser beam power is applied $(P=600 \mathrm{~W})$ with initial gouache coating and $\mathrm{CO}_{2}$ cooling system, in obtained laser track cracks can be seen which are probably connected with high stresses caused by the cooling rate. Crack were not observed on laser tracks if laser beam power was increased to $1000 \mathrm{~W}$ or $1400 \mathrm{~W}$.
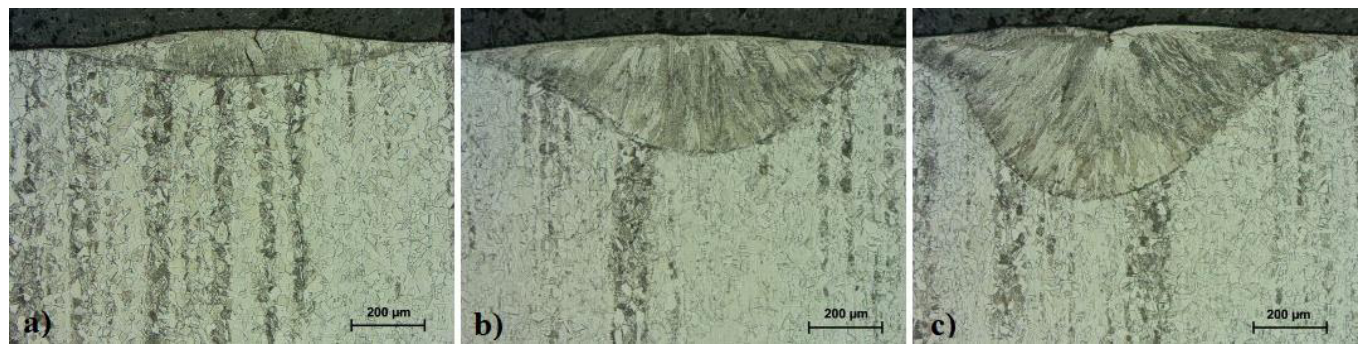

Figure 4. Microstructure of 1.4550 steel after impact of laser beam with initial gouache coating and with cooling using $\mathrm{CO}_{2}$ during laser heat treatment; a) $600 \mathrm{~W}$, b) $1000 \mathrm{~W}$ c) $1400 \mathrm{~W}$ 
The influence of applied technological parameters on dimensions of laser tracks (depth, width) for 1.4450 steel after laser heat treatment are shown in table 2.

Table 2. Dimensions of laser tracks after laser heat treatment with applied parameters for 1.4550 steel

\begin{tabular}{|c|c|c|c|c|}
\hline Track's depth & Track's width & $P$ & & \\
\hline$[\mu \mathrm{m}]$ & {$[\mu \mathrm{m}]$} & {$[\mathbf{W}]$} & Coating & Cooning \\
\hline 116 & 901 & 600 & \multirow{6}{*}{ gouache } & \multirow{3}{*}{ none } \\
\hline 327 & 1188 & 1000 & & \\
\hline 458 & 1193 & 1400 & & \\
\hline 127 & 959 & 600 & & \multirow{3}{*}{$\mathrm{CO}_{2}$} \\
\hline 327 & 1207 & 1000 & & \\
\hline 472 & 1276 & 1400 & & \\
\hline 154 & 971 & 600 & \multirow{6}{*}{ none } & \multirow{3}{*}{$\mathrm{CO}_{2}$} \\
\hline 305 & 1277 & 1000 & & \\
\hline 513 & 1362 & 1400 & & \\
\hline 134 & 929 & 600 & & \multirow{3}{*}{ none } \\
\hline 332 & 1176 & 1000 & & \\
\hline 496 & 1355 & 1400 & & \\
\hline
\end{tabular}

Figure 5 presents microhardness profiles obtained in laser tracks and core of 1.4550 steel with applying variable parameters of treatment, i.e. laser beam power. Microhardness for each analyzed cases were similar. Here, for example, results for specimens with gouache coating and without applying cooling system during laser heat treatment are shown. Depth of re-melted zone is marked in diagram with dashed line. Microhardness of laser tracks, despite of differences in structure due to re-melting was comparable and equal to approximately $200 \mathrm{HV}$.

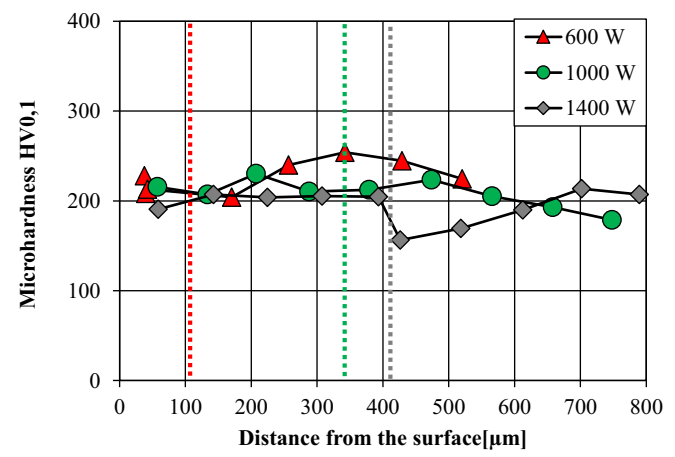

Figure 5. Microhardness profiles for 1.4550 steel covered with gouache coating and laser heat treated without cooling system during the process

On the basis of carried out research it can be seen that as a result of laser beam impact microstructure in re-melted zone is dendritic which is susceptible to machining. In re-melted zone direction of dendritic growth can be clearly seen and it has its beginning on boundary between re-melted zone and grains of the substrate. Obtained results of microhardness does not show significant differences between core and re-melted material, therefore, in further research, attempts connected with manufacturing multiple laser tracks will be taken and these will be machined in the next step.

\section{Conclusions}

On the basis of the carried out investigations, the following conclusion are formulated:

- with increasing the laser beam power dimensions of laser tracks also increase. Depth of laser tracks changes significantly in comparison with its width. 
- The highest depth of re-melted zone was observed for material which was not covered with initial coating and if cooling system was not applied

- Microhardness in re-melted zone and in the substrate was similar

\section{Acknowledgments}

The presented research results, executed under the domestic project LIDER of No. 164/L$6 / 14 / \mathrm{NCBR} / 2015$ with grants for education allocated by the National Centre for Research and Development.

\section{References}

1. Z. Zhu, V.G. Dhokia, A. Nassehi, S.T. Newman, International Journal of Computer Integrated Manufacturing 26 (2013)

2. R.A. Rahman Rashid, S. Sun, G. Wanga, M.S. Dargusch, International Journal of Machine Tools \& Manufacture 63 (2012)

3. Y. Jeon, C. M. Lee, International Journal of Precision Engineering and Manufacturing 13 (2012)

4. P. Dumitrescu, P. Koshy, J. Stenekes, M.A. Elbestawi, International Journal of Machine Tools \& Manufacture 46 (2006)

5. C. R. Dandekar, Y.C. Shin, Int J Adv Manuf Technol 66 (2013)

6. D. Przestacki, M. Kuklinski, A. Bartkowska, INT J ADV MANUF TECHNOL, 93 (2017)

7. A. Bartkowska, M. Kukliński, P. Kieruj, MATEC Web of Conferences, MSE 121, 03006 (2017)

8. A. Bartkowska, A. Pertek, M. Popławski, D. Bartkowski, D. Przestacki, A. Miklaszewski, OPT LASER TECHNOL., 72 (2015)

9. A. Bartkowska; A. Pertek, Surface and Coatings Technology, 248 (2014)

10. D. Przestacki, M. Jankowiak, Journal of Physics: Conference Series 483 (2014)

11. M. Kawalec, D. Przestacki, D.,K. Bartkowiak, M. Jankowiak, ICALEO 2008 - 27th Inter.Congress on Applications of Lasers and Electro-Optics, Congress Proceedings, (2008)

12. D. Przestacki, T. Chwalczuk, S. Wojciechowski, INT J ADV MANUF TECHNOL, 91 (2017)

13. H. Ding, Y. C. Shin, Int J Adv Manuf Technol 64 (2013)

14. S. Sun, M. Brandt, M.S. Dargusch, International Journal of Machine Tools \& Manufacture 50 (2010)

15. D. Bartkowski, A. Młynarczak, A. Piasecki, B. Dudziak, M. Gościański, A. Bartkowska, OPT LASER TECHNOL. 68 (2015)

16. Y. Xiong, W. Wang, R. Jiang, K. Lin, M. Shao, Materials, Vol.11(4)(2018)

17. K. Venkatesan, R. Ramanujam, P. Kuppan, Int J Adv ManufTechnol, Vol.91:3807-3821(2017)

18. D. Przestacki, T. Chwalczuk, MATEC Web of Conferences 136 (2017)

19. S. Wojciechowski, P. Twardowski, T. Chwalczuk, Journal of Physics: Conference Series, 20140000, Vol.483, pp.1-8(2014) 